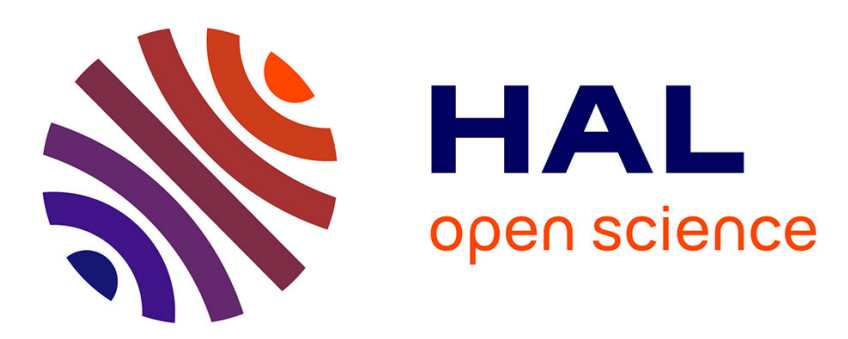

\title{
IDO1 and TDO inhibitory evaluation of analogues of the marine pyrroloiminoquinone alkaloids:wakayin and tsitsikammamines
}

Thomas Levy, Laura Marchand, Vincent Stroobant, Luc Pilotte, Benoît van den Eynde, Frédéric Rodriguez, Evelyne Delfourne

\section{To cite this version:}

Thomas Levy, Laura Marchand, Vincent Stroobant, Luc Pilotte, Benoît van den Eynde, et al.. IDO1 and TDO inhibitory evaluation of analogues of the marine pyrroloiminoquinone alkaloids:wakayin and tsitsikammamines. Bioorganic \& Medicinal Chemistry Letters, 2021, 40, pp.127910. 10.1016/j.bmcl.2021.127910 . hal-03064757

\section{HAL Id: hal-03064757 https://hal.science/hal-03064757}

Submitted on 14 Dec 2020

HAL is a multi-disciplinary open access archive for the deposit and dissemination of scientific research documents, whether they are published or not. The documents may come from teaching and research institutions in France or abroad, or from public or private research centers.
L'archive ouverte pluridisciplinaire HAL, est destinée au dépôt et à la diffusion de documents scientifiques de niveau recherche, publiés ou non, émanant des établissements d'enseignement et de recherche français ou étrangers, des laboratoires publics ou privés. 


\title{
IDO1 and TDO inhibitory evaluation of analogues of the marine pyrroloiminoquinone alkaloids:wakayin and tsitsikammamines
}

Thomas Levy ${ }^{\mathrm{a}}$, Laura Marchand ${ }^{\mathrm{a}}$, Vincent Stroobant ${ }^{\mathrm{b}}$, Luc Pilotte ${ }^{\mathrm{b}}$, Benoît Van den Eynde ${ }^{\mathrm{b}}$, Frédéric Rodriguez ${ }^{\mathrm{a}}$ and Evelyne Delfourne ${ }^{\mathrm{a}, *}$

a)Université Paul Sabatier, UMR CNRS 5068, Laboratoire de Synthèse et Physicochimie de Molécules d'Intérêt Biologique, 118 Route de Narbonne, 31062 Toulouse Cédex 9, France.

b)Ludwig Cancer Research Ltd (Brussels Branch) \& de Duve Institute (Tumor Immunology \& Antigen Processing group), Avenue Hippocrate 74 (UCL B1.7403) B-1200 Bruxelles, Belgique.

\begin{abstract}
:
Indoleamine 2,3-dioxygenase (IDO1) and tryptophane 2,3-dioxygenase (TDO) are two hemecontaining enzymes which catalyze the conversion of tryptophan to $\mathrm{N}$-formylkynurenine. Both enzymes are well establish therapeutic targets as important factors in the tumor immune evasion mechanism. A number of analogues of the marine pyrroloquinoline alkaloids tsitsikammamines or wakayin have been synthesized, two of them being issued from an original method to build the bispyrroloquinone framework. All the derivatives were evaluated in a cellular assay for their capacity to inhibit the enzymes. Six compounds have shown a significant potency on HEK 293-EBNA cell lines expressing hIDO1 or hTDO.
\end{abstract}

Keywords: marine alkaloids, pyrroloiminoquinone, bispyrroloquinone, wakayin, tsitsikammamine, IDO1 and TDO.

\footnotetext{
* Corresponding author, Tel 33561556293 ; Fax 33561556011

E-mail : delfourn@chimie.ups-tlse.fr
} 


\section{Introduction}

In the recent period, immunotherapy has proven to be a promising method for cancer treatment. Among the enzymes involved in the mechanisms allowing tumors to resist or escape immune rejection, indoleamine-2,3-dioxygenase (IDO1) and tryptophane-2,3dioxygenase (TDO) play an essential role. ${ }^{1,2}$ They are two main enzymes which catalyse the rate-determining first step of the tryptophan catabolization along the Kynurenine pathway. Despite the continuous efforts to develop IDO1 and TDO inhibitors, only nine compounds have reached clinical trials ${ }^{3}$, of which, only two target both the two enzymes. This indicates that there is still an urgent need for the discovery of new molecules with this mode of action.

Exiguanine A, a marine alkaloid isolated from the sponge Neopetrosia exigua, has been reported so far, as the most potent IDO1 inhibitor issued from natural source $(\mathrm{Ki}=41$ $\mathrm{nM}){ }^{4}$ In our group we are interested in a family of alkaloids, mainly found in sponges and ascidians, based on the pyrrolo[4,3,2-de]quinolone scaffold, and more particularly in a subgroup of this class of compounds including wakayin ${ }^{5}$ and tsitsikammamines $\mathrm{A}$ and $\mathrm{B}^{6}$, which possess a unique tetracyclic bispyrroloiminoquinone ring system.<smiles>C[C@H]1CCN(C)c2cc3c(c(O)c21)O[C@]1(C(=O)N(C)C(=O)N1C)C1=C3C(=O)c2[nH]cc(CCN)c2C1=O</smiles><smiles>O=C1C=CC2=NCCc3c[nH]c1c32</smiles>

pyrrolo[4,3,2-de]quinolone<smiles>O=C1C(=O)c2[nH]cc(-c3c[nH]c4ccccc34)c2C2=NCCc3c[nH]c1c32</smiles><smiles></smiles>

wakayin tsitsikammamine $A, R_{1}=R_{2}=H$ tsitsikammamine $B, R_{1}=H, R_{2}=M e$ methoxytsitsikammamine, $\mathrm{R}_{1}=\mathrm{Me}, \mathrm{R}_{2}=\mathrm{H}$

Figure 1: Alkaloids issued from marine source 
As part of our research program to define new anticancer agents, we were led to study IDO1 and TDO inhibitory activities of tsitsikammamines analogues involved in the synthesis of tsitsikammamine A. ${ }^{7,8}$ Some of the compounds described, including methoxytsitsikammamine have shown submicromolar potency in an enzymatic assay whereas a number of other were also active against IDO1 in a cellular assay. ${ }^{9}$ Recently, the structurally related derivative Roxyl-WL which constitutes one of the most highly potent and selective inhibitor targeting IDO1 discovered so far $\left(\mathrm{IC}_{50}=1 \mathrm{nM}\right)$, has been described. ${ }^{10}$

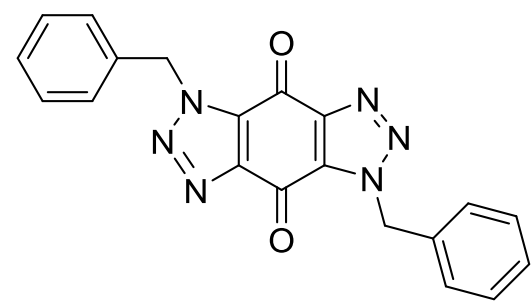

Figure 2: Roxyl-WL

This context prompted us to evaluate IDO1 and TDO inhibitory potency of compounds 1-20 in a cellular assay, the results are reported herein.<smiles>CCCCc1c[nH]c2ccccc12</smiles>

1 iso 1 2 iso 2

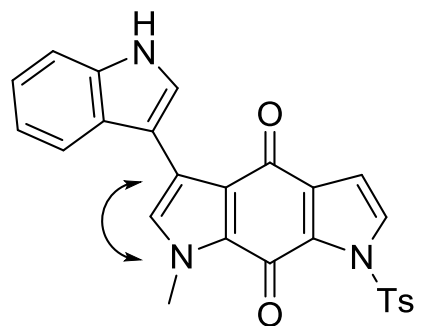

3 iso 1

4 iso2<smiles>[R]C(=O)c1[nH]c2c(c1C([R])=O)C(=O)c1ccn([3H])c1C2=O</smiles>

$5 \mathrm{R}=\mathrm{Ph}$ $6 \mathrm{R}=\mathrm{Ph}(\mathrm{OMe})$ $7 \mathrm{R}=$ indole<smiles></smiles>

$8 \mathrm{R}=\mathrm{Ts}$

$9 \mathrm{R}=\mathrm{H}$
$10 R_{1}=T s, R_{2}=R_{3}=H$, iso 1

$11 R_{1}=T s, R_{2}=R_{3}=H$, iso2

$12 R_{1}=R_{2}=R_{3}=H$, iso2

$13 R_{1}=T s, R_{2}=H, R_{3}=P h$, iso 1

$14 R_{1}=T s, R_{2}=H, R_{3}=P h$, iso2

$15 R_{1}=H, R_{2}=H, R_{3}=P h$, iso1

$16 \mathrm{R}_{1}=\mathrm{Ts}, \mathrm{R}_{2}=\mathrm{H}, \mathrm{R}_{3}=\mathrm{Ph}(\mathrm{OH})$, iso 1

$17 \mathrm{R}_{1}=\mathrm{Ts}, \mathrm{R}_{2}=\mathrm{H}, \mathrm{R}_{3}=\mathrm{Ph}(\mathrm{OH})$, iso2

$18 R_{1}=H, R_{2}=H, R_{3}=P h(O H)$, iso1

$19 \mathrm{R}_{1}=\mathrm{Ts}, \mathrm{R}_{2}=\mathrm{Me}, \mathrm{R}_{3}=\mathrm{H}$

$20 \mathrm{R}_{1}=\mathrm{Ts}, \mathrm{R}_{2}=\mathrm{H}, \mathrm{R}_{3}=\mathrm{O}=$

Figure 3: Analogues of the marine alkaloids wakayin and tsitsikammamine 


\section{Results and discussion}

\section{Chemistry}

Compounds 1-4 were prepared by adapting the reaction sequence previously reported by Zhang et al., the methoxy-naphtoquinone being replaced by $\mathrm{N}$-tosylindoledione $21 .{ }^{11}$

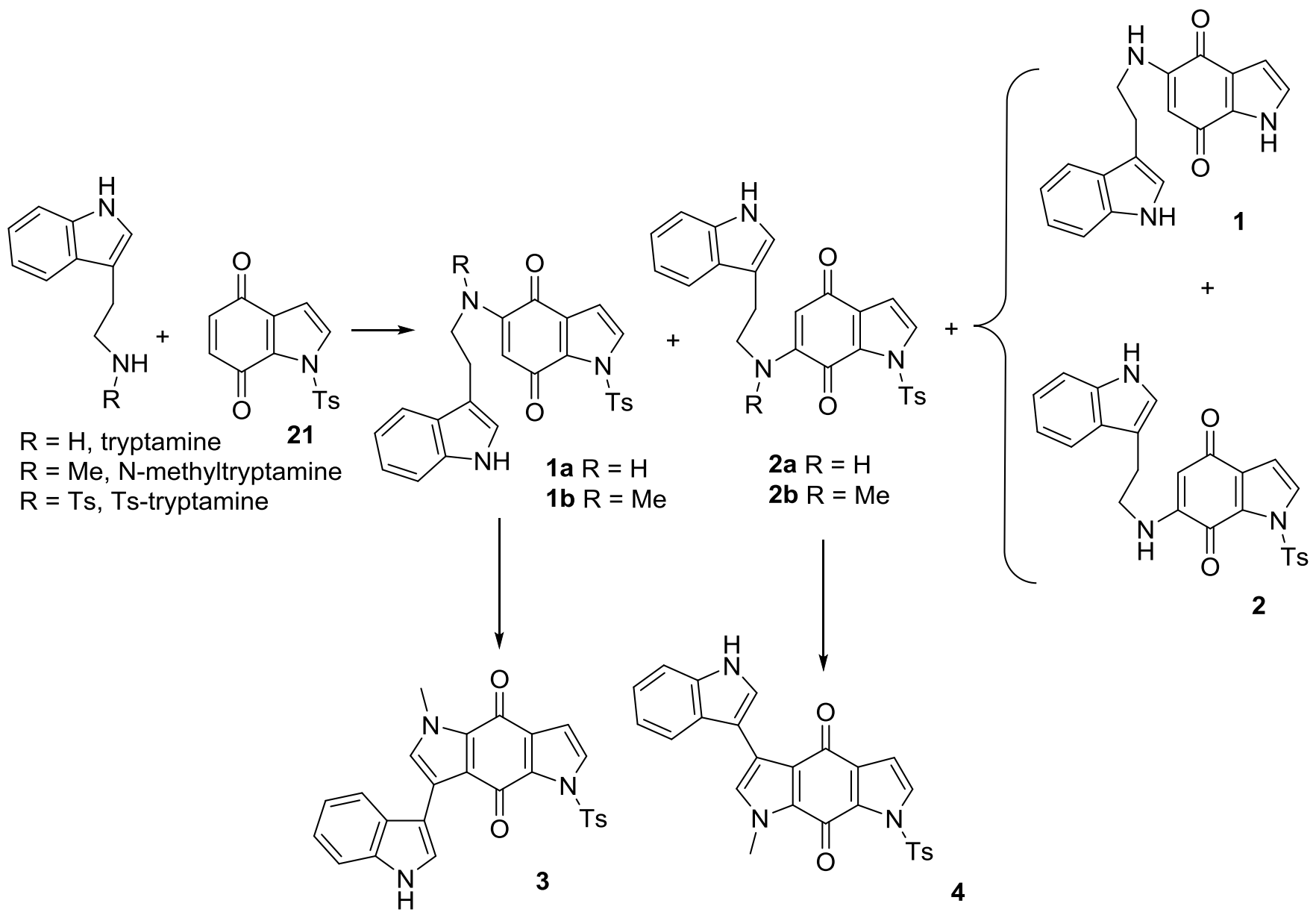

Scheme 1: Synthesis of analogues 1-4

In the first step, the tosylindoledione $\mathbf{2 1}$ was condensed with tryptamine to give a mixture of two regioisomers $\mathbf{1 a}$ and $\mathbf{2 a}$ both with their corresponding detosylated analogues $\mathbf{1}$ and $\mathbf{2}$ in 8 , 11,46 and $22 \%$ yield respectively. It has to be noted that tosyltryptamine was isolated as a byproduct. ${ }^{12}$ The same reaction in which tryptamine was replaced by $\mathrm{N}$-methyl tryptamine led to compounds $\mathbf{1 b}$ and $\mathbf{2 b}$ which were subsequently reacted with DDQ to form derivatives $\mathbf{3}$ and 4 (28 and $75 \%$ yield respectively). The structural assignment of these compounds was achieved from a previously described empirical method. ${ }^{13}$ It has to be noted that this last synthetic sequence constitutes a new strategy to build the bispyrroloquinonic framework. Derivatives 5-7 were obtained by action of $\mathbf{2 1}$ on different $\alpha$-ketoamines ${ }^{14}$, whereas pyrazolic 
analogues 8-20 have been prepared on the basis of a [3+2] dipolar cycloaddition reaction between various quinones and diazo species as previously reported by our group. ${ }^{15,16}$ Thus, compounds $\mathbf{8}$ and $\mathbf{9}$ were issued from the reaction involving indoledione $\mathbf{2 1}$ and the diazoaminopropane derivative 22, and compounds 10-20 resulted from the reaction of indoledione 23 with diazo-derivatives 24.<smiles>[R]C(=O)c1[nH]c2c(c1C([R])=O)C(=O)c1ccn([As])c1C2=O</smiles>

5-7<smiles>[R]C(=O)CN</smiles>

21<smiles>C=CCn1cc2c(c1C(=O)N([13CH3])C=C)C(=O)c1[nH]nc(CCN)c1C2=O</smiles>

8,9<smiles></smiles>

13-20

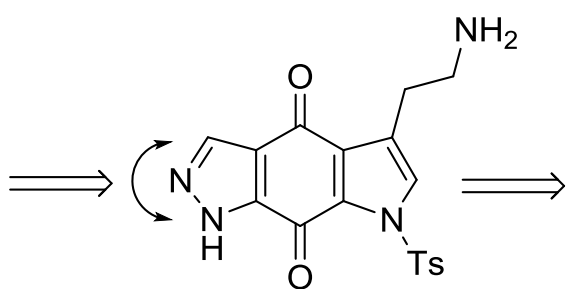

s<smiles>C1CC1</smiles>

24<smiles>Cn1cc(CCNC(C)(C)C)c2c1C(=O)C=CC2=O</smiles>

23

Scheme 2: Synthesis of bispyrroloquinonic and pyrrazolic analogues

\section{Bioactivity assay}

The synthesized derivatives were evaluated for their ability to inhibit tryptophane degradation and kynurenine production in HEK 293-EBNA cell lines expressing hIDO1 or hTDO cell lines expressing IDO1 and TDO. This global cellular assay is informative for drug development, as it evaluates a combination of the drugs' TDO/IDO inhibitory potency, their potential cytotoxicity, the inhibition of tryptophan transporters, and the effects of their metabolites. The assay was performed as previously described, the results are reported in Table1. ${ }^{17}$ 
Table 1: Inhibition and cell viability data for wakayin and tsitsikammamine analogues

\begin{tabular}{|c|c|c|c|c|c|c|c|c|c|c|c|c|}
\hline \multirow[t]{3}{*}{ Compounds } & \multirow{2}{*}{\begin{tabular}{|c|} 
Viability \\
$25 \mu \mathrm{M}$
\end{tabular}} & IDO & TDO & \multirow{2}{*}{\begin{tabular}{|l|} 
Viability \\
$12,5 \mu \mathrm{M}$
\end{tabular}} & IDO & TDO & \multirow{2}{*}{$\begin{array}{l}\text { Viability } \\
6,25 \mu \mathrm{m}\end{array}$} & IDO & TDO & \multirow{2}{*}{$\begin{array}{l}\text { Viability } \\
3,12 \mu \mathrm{M}\end{array}$} & IDO & TDO \\
\hline & & \multicolumn{2}{|c|}{$25 \mu \mathrm{M}$} & & \multicolumn{2}{|c|}{$12,5 \mu \mathrm{M}$} & & \multicolumn{2}{|c|}{$6,25 \mu \mathrm{M}$} & & \multicolumn{2}{|c|}{$3,12 \mu \mathrm{M}$} \\
\hline & mean & mean & mean & mean & mean & mean & mean & mean & mean & mean & mean & mean \\
\hline 1 & 26 & 39 & 67 & 56 & 38 & 31 & 69 & 28 & 12 & 75 & 23 & 5 \\
\hline 2 & 84 & 11 & 0 & 99 & 13 & 0 & 98 & 9 & -3 & 98 & 2 & -8 \\
\hline 3 & 95 & 28 & -8 & 97 & 26 & -1 & 98 & 20 & 2 & 100 & 12 & 2 \\
\hline 4 & 88 & 27 & -3 & 96 & 21 & 0 & 96 & 12 & 3 & 98 & 8 & 2 \\
\hline 5 & 111 & 61 & 28 & 102 & 62 & 55 & 125 & 58 & 27 & 99 & 52 & 15 \\
\hline 6 & 100 & 63 & -1 & 105 & 63 & 3 & 97 & 63 & 6 & 94 & 61 & 4 \\
\hline 7 & 75 & 24 & -9 & 82 & 25 & -2 & 81 & 22 & 1 & 87 & 16 & -1 \\
\hline 8 & 67 & -88 & -35 & 85 & -80 & -34 & 88 & -58 & -28 & 87 & -55 & -19 \\
\hline 9 & 115 & -3 & 3 & 110 & -4 & -6 & 98 & -3 & -7 & 107 & 0 & -7 \\
\hline 10 & 91 & 6 & 7 & 97 & 9 & 13 & 91 & 9 & 14 & 92 & 10 & 12 \\
\hline 11 & 93 & 11 & 15 & 110 & 15 & 23 & 106 & 12 & 19 & 87 & 10 & 15 \\
\hline 12 & 90 & -1 & 9 & 91 & 0 & 8 & 92 & 2 & 8 & 93 & 2 & 6 \\
\hline 13 & 78 & 18 & -10 & 79 & 16 & 2 & 95 & 12 & 5 & 91 & 10 & 5 \\
\hline 14 & 96 & 23 & 21 & 123 & 22 & 18 & 126 & 19 & 13 & 91 & 14 & 10 \\
\hline 15 & 84 & 5 & 5 & 94 & 5 & 6 & 93 & 4 & 5 & 93 & 4 & 3 \\
\hline 16 & 63 & 18 & 12 & 65 & 11 & -4 & 80 & 7 & -2 & 87 & 5 & -3 \\
\hline 17 & 136 & 20 & 0 & 121 & 14 & -10 & 86 & 6 & -6 & 90 & 3 & -8 \\
\hline 18 & 84 & 3 & 1 & 96 & 2 & -4 & 98 & 0 & 0 & 103 & -1 & -9 \\
\hline 19 & 72 & 36 & 35 & 77 & 23 & 21 & 89 & 16 & 18 & 93 & 11 & 3 \\
\hline 20 & 31 & 14 & 27 & 84 & 1 & 6 & 107 & 3 & 5 & 104 & 1 & -7 \\
\hline
\end{tabular}

IDO and TDO cell assay inhibition: Inhibitory activity (\%) was estimated by measuring tryptophan degradation and kynurenine production in the supernatant of 24-h cultures performed in the presence of compound at different concentrations. Tryptophan and kynurenine were measured by HPLC. Cell viability (\%) was estimated by an MTS/PMS assay in the same cultures. The indicated values are the result of two independent determinations.

Among the twenty compounds tested in the present study, six: 1, 3, 5, 6, 7 and 19 exhibit inhibitory activities ranging from 23 to $63 \%$ against IDO1 at $12.5 \mu \mathrm{M}$ with only two of which 5 and 6 retain good activity when their concentration was reduced to $3.12 \mu \mathrm{M}$. Three of these derivatives $\mathbf{1}, \mathbf{5}$ and $\mathbf{1 9}$ are also active against TDO at the same concentration. It seemed relevant to us to compare these results with those obtained for tsitsikammamine analogues which were the subject of a previous work (Figure 4). ${ }^{9}$ Compounds $\mathbf{1}$ and $\mathbf{2 1}$ which are open structures have the same inhibition capacity against IDO, the nature of the aromatic substituent at the end of the chain and the presence of a hydroxyl group does not seem to have much influence on the activity. Compounds $\mathbf{3}$ and $\mathbf{4}$ are less active than their counterpart compounds in which the second five-membered cycle is not aromatic. This is in agreement with the previous observation which showed that the fully aromatic analogue of $\mathbf{2 2 b}$ had an 
activity reduced by half. None of the aza-analogues evaluated in this work, except compound 19, showed activity against IDO, 19 inhibiting the enzyme to a moderate level. In general, contrary to what one would have expected, given the activity of Roxyl-WL, the replacement of a pyrrole ring by a pyrrazole ring, did not lead to better inhibitors.

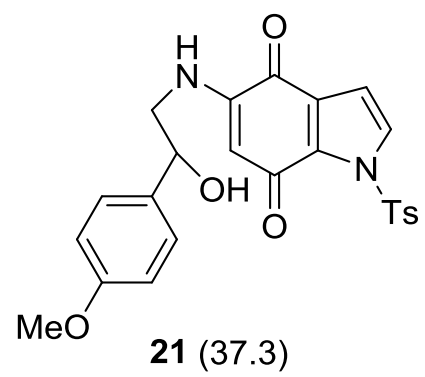

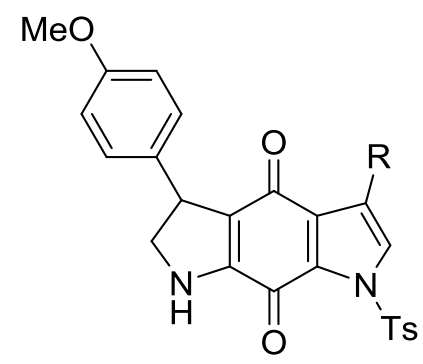

22a, $\mathrm{R}=\mathrm{H}(54.2)$

22b, $\mathrm{R}=\mathrm{H}(40.2)$

23a, $\mathrm{R}=\mathrm{CH}_{2} \mathrm{CH}_{2} \mathrm{NH}_{2}(40.2)$
$\mathrm{MeO}$

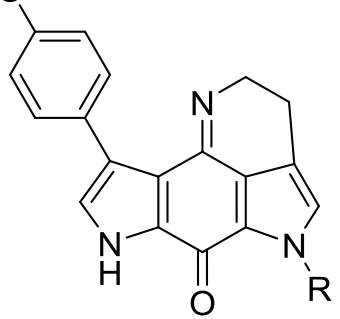

$R=T s, 24(32)$

$\mathrm{R}=\mathrm{H}, \mathbf{2 5 b}(19.4)$

Figure 4: Tsitsikammamine analogues studied in a previous work and exhibiting the best inhibitory activities (the percentage obtained at $10 \mu \mathrm{M}$ is indicated in brackets), a and $b$ refer to iso1 and iso2.

The best IDO1 inhibitors in this series and in this family so far, are compounds $\mathbf{5}$ and $\mathbf{6}$ which are also the only ones comprising an additional substituent in $\alpha$-position of the nitrogen of the substituted pyrrole ring.

Three derivatives 1, 5 and $\mathbf{1 9}$ are dual inhibitors, as they also show activity against TDO, the most active being compound $\mathbf{5}$ whereas none were active in the previous series.

\section{Molecular docking}

In order to understand the affinity observed within IDO1, we studied the binding mode of compounds by molecular docking ${ }^{18}$ using Molegro Virtual Docker program. ${ }^{19}$ Prior to modelling studies, a classification of know Protein Data Bank (PDB) ${ }^{20}$ structures related to Uniprot P14902 domain ${ }^{21}$ was done. The PDB structures were split and all chains structurally aligned against $2 \mathrm{D} 0 \mathrm{~T}^{22}$ (chain A, formerly 2D0Ta) using UCSF Chimera/MatchMaker. ${ }^{23,24}$ The resulting 52 chains were clustered using a combination of descriptors at protein or ligand levels, resulting in five groups. The 2DTOa (used for structural alignment) and 5EK2 $\mathrm{a}^{25}$ (used for docking as target) were included in the same group (5EK2a being the representative of a sub-cluster characterized by a binding cavity a little more opened). Two docking protocols 
were used: P1-GPU for screening and P2-OPT (full flexibility of binding site) for investigating the best compounds 5 and $\mathbf{6}$ (supplementary data for the overall in silico processes). The key interactions stabilizing the compounds within the IDO binding cleft are depicted in Figures 5 and 6 respectively (2D interactions diagrams are available in supplementary data).

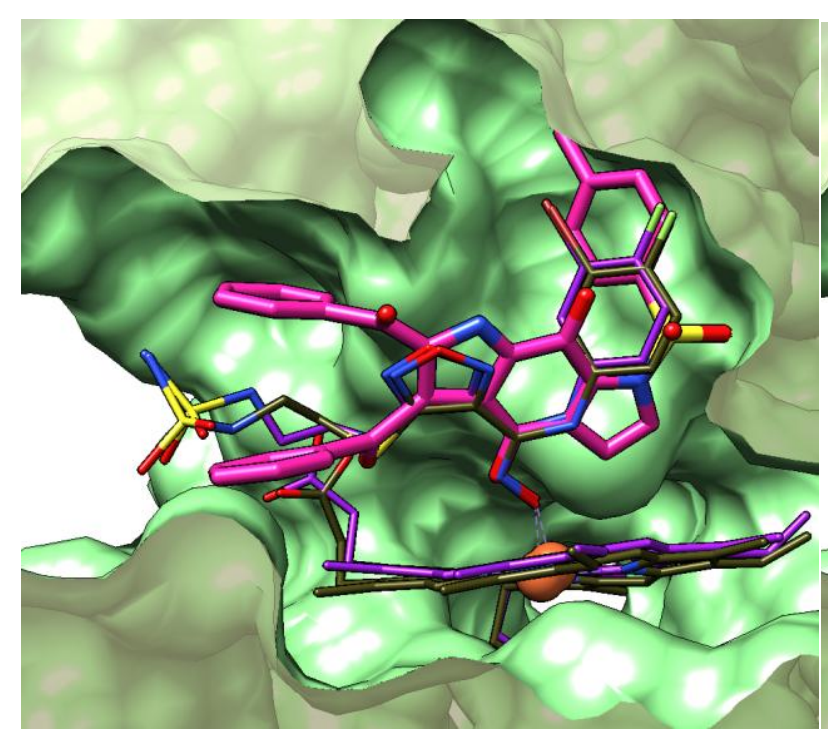

Figure 5: Best 5 docked pose (pink, big sticks) of 5 in 5EK2a binding site (light green, molecular surface) relatively to crystallographied ligands BBJ (purple, from 6E40, chain A) and HQS (kaki, from 6E41, chain A) after structural alignment.

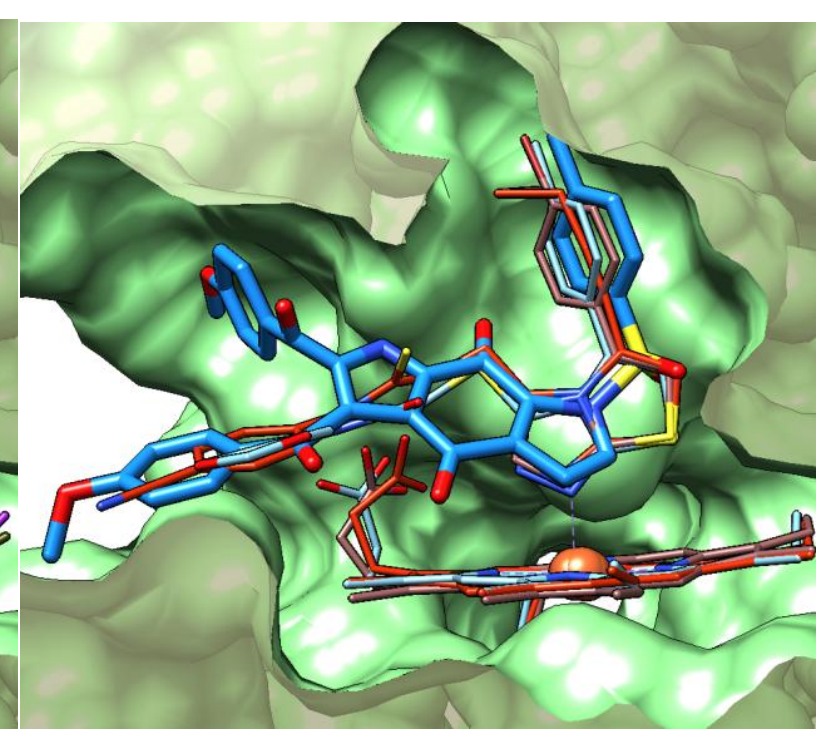

Figure 6: Best 6 docked pose (blue, big sticks) of $\mathbf{6}$ in 5EK2a binding site (light green, molecular surface) relatively to crystallographied ligands DO9 (red, from 6KOFa), PKJ (light blue, from 4PK5a) and DYC (brown, from 6KW7a) after structural alignment.

BBJ and HQS are found in PDB structures 6E40 and 6E41. ${ }^{26}$ These two structures are classified in the same cluster 2D0Ta. The tosyl (Ts) group allows the classical L shaped form upper the heme's plane and shows interactions (hydrogen bonds) with SER167 and TYR126. The cycles (Ts and bispyrrololoquinonic frame) are found in the same plane as most of the IDO1 ligands complexed with heme whereas the phenyl groups share non unusual placement with compounds found in structures of IDO1 at entry of binding cavity (Figure 6 for an example). Interestingly, one of the two carbonyl groups of $\mathbf{5}$ is aligned with the hydroxylamine of BBJ and HQS.

The best pose of $\mathbf{6}$ is different from its counterpart $\mathbf{5}$, but shares the overall $\mathrm{T}$ shaped form, allowed by the placement of Ts group inside the cavity and normal to the heme. The Ts group exhibits the same interaction (hydrogen bond) with SER167. Some similarities (shape, planes) 
are found with known ligands of IDO1, particularly D09, PKJ and DYC from 4PK5 (chain A), 6KOF (chain A) and 6KW7 (chain A) respectively. ${ }^{27,28}$ These protein structures are classified in the same cluster than 5EK2a used for the docking studies. The pattern of interactions is different from the one of $\mathbf{5}$, with more involvement of Pi (cycles, cations, sulfur) interactions. Interestingly, one of five-membered cycles of $\mathbf{6}$ is very well placed over the heme center, even if a nitrogen atom is not found in front of the Fe.

In conclusion, derivatives of marine pyrroloquinolines wakayin and tsitsikammamine have shown in a cell-based assay, interesting inhibitory activity on IDO1 and TDO, two enzymes involved in tumoral immune resistance. A molecular modeling study of compounds $\mathbf{5}$ and $\mathbf{6}$ in the IDO1active site gives insights to optimize these compounds. Particularly the impact of one of the two carbonyl groups of $\mathbf{5}$ close enough to Fe could be investigated to make electrostatic interactions as in the case of the hydroxylamine group of BBJ. In compound $\mathbf{6}$, the replacement of a carbon by a nitrogen capable of dative bonding with Fe would be a first approach before further optimizing the compound to create a second interaction involving the carboxyl group of heme.

\section{References}

1- Brochez, L.; Chevolet, I.; Kruse, V. Eur. J. Cancer, 2017, 76, 167-182.

2- Ye, Z.; Yue, L.; Shi, J.; Shao, M.; Wu, T. J. Cancer, 2019, 10, 2771-2782.

3- Labadie, B. W.; Bao, R.; Luke, J. J. Clin. Cancer Res. 2019, 25, 1462-1471.

4- Carr, G., Chung, M. K. W.; Mauk, A. G.; Andersen R. J. J. Med. Chem. 2008, 51, 2634-2637.

5- Copp, B. R.; Ireland, C. M.; Barrows, L. R. J. Org. Chem. 1991, 56, 4596-4597.

6- Hooper, G. J.; Davies-Coleman, M. T.; Borges, K.; Coetze, P. S. Tetrahedron Lett. 1996, 37, 7135-7138

7- Rives, A.; Delaine, T.; Legentil, L.; Delfourne, E. Tetrahedron Lett. 2009, 50, 1128.

8- Rives, A.; Le Calvé, B.; Delaine, T.; Legentil, L. Kiss, R.; Delfourne, E. Eur. J. Med. Chem. 2010, 45, 343.

9- Dolusic, E.; Larrieu, P.; Meinguet, C.; Colette, D.; Rives, A.; Blanc, S.; Ferain, T.; Pilotte, L. ; Stroobant, V. ; Wouters, J. ; Van den Eynde, B.; Masereel, B. ; Delfourne, E.; Frédérick, R. Bioorg. Med. Chem. Lett. 2013, 23, 47-54. 
10- Xu, G.; Wang, T.; Li, Y. ; Huang, Z. ; Wang, X. ; Zheng, J.; Yang, S.; Fan, Y.; Xiang, R. J. Enz. Inhib. Med. Chem. 2018, 33, 1089-1094.

11-Zhang L.; Cava, M. P.; Rogers, R. D.; Rogers, L. M. Tetrahedron Lett, 1998, 39, 7677

12- Farwaha, H. S.; Bucher, G.; Murphy, J. A. Org. Biomol. Chem. 2013, 11, 8073-8081

13- Chassaing, S.; Delfourne, E. Magn. Res. Chem. 2010, 47, 9.

14- Vanicat, A.; André-Barrès, C.; Delfourne, E. Tetrahedron Letters 2017, 58, 342-345.

15- Legentil, L.; Lesur, B.; Delfourne, E. Bioorg. Med. Chem. Lett. 2006, 16, 427.

16- Legentil, L.; Benel, L.; Bertrand, V.; Lesur, B.; Delfourne, E. J. Med. Chem. 2006, 49, 2979.

17-Luc Pilotte, L; Larrieu, P.; Stroobanta, V.; Colaua, D.; Dolušic, E.; Frédérick, R. ; De Plaena, E. ; Uyttenhovea, C. ; Wouters, J. ; Bernard Masereel, B. ; Van den Eynde, B. PNAS 2012, 109, 2497-2502.

18-Sousa, S. F.; Ribeiro, A. J. M.; Coimbra, J. T. S.; Neves, R. P. P.; Martins, S. A.; Moorthy, N. S. H. N.; Fernandes, P. A.; M.J. Ramos, P. A. Curr. Med. Chem. 2013, 20: 2296-2314.

19- Thomsen, R.; Christensen, M. H. J. Med. Chem. 2006, 49, 3315-3321.

20- Berman, H. M.; Westbrook, J.; Feng, Z.; Gilliland, G.; Bhat, T. N.; H. Weissig, N.; Shindyalov, I. N.; Bourne, P. E. Nucleic Acids Research 2000, 28, 235-242.

21- The UniProt consortium. Nucleic Acids Res. 2019, 47, D506-515.

22-Sugimoto, H.; Oda, S. I.; Otsuki, T.; Hino, T.; Yoshida, T.; Shiro, Y. Proc Natl Acad Sci USA 2006, 103, 2611-2616.

23-Pettersen, E. F.; Goddard, T. D.; Huang, C. C.; Couch, G. S.; Greenblatt, D. M.; E.C. Meng, Ferrin, T. E. J. Comput. Chem. 2004, 25, 1605-1612.

24-Meng, E. C.; Pettersen, E. F; Couch, G. S.; Huang, C. C.; Ferrin, T. R. BMC Bioinformatics 2006, 7, 339-349.

25-Peng, Y. H.; Ueng, S. H.; Tseng, C. T.; Hung, M. S.; Song, J. S.; Wu, J. S.; Liao, F. Y.; Fan, Y. S.; Wu, M. H.; Hsiao, W. C.; Hsueh, C. C.; Lin, S. Y.; Cheng, C. Y.; Tu, C. H.; Lee, L. C.; Cheng, M. F.; Shia, K. S.; Shih, C.; Wu, S. Y.; Y.H. Peng, Y. H. J. Med. Chem. 2016, 59, 282-293.

26-Luo, S.; Xu, K.; Xiang, S.; Chen, J.; Chen, C.; Guo, C.; Tong, Y.; Tong, L. Acta Crystallogr. F Struct. Biol. Commun. 2018, 74, 717-724.

27-Tojo, S.; Kohno, T.; Tanaka, T.; Kamioka, S.; Ota, Y.; Ishii, T.; Kamimoto, K.; Asano, S.; Isobe, Y. ACS Med. Chem. Lett. 2014, 5, 1119-1123. 
28- ] Peng, Y. H.; Liao, F. Y.; Tseng, C. T.; Kuppusamy, R.; Li, A. S.; Chen, C. H.; Fan, Y. S.; Wang, S. Y.; Wu, M. H.; Hsueh, C. C.; Chang, J. Y.; Lee, L. C.; Shih, C.; Shia, K. S.; Yeh, T. K.; Hung, M. S.; Kuo, C. C.; Song, J. S.; Wu, S. Y.; Ueng, S. H. J. Med. Chem. 2020, 63, 1642-1659. 